\title{
Effect of Nozzle Parameters on the Temperature Field, Flow Field and Stress Field in the Continuous Casting of Steel Billet
}

\author{
Pinghu Chen ${ }^{1,2, ~ a, ~ R u i q i n g ~} \mathrm{Li}^{2,3, b, ~}{ }^{\text {, }}$, Ripeng Jiang ${ }^{2,3, \mathrm{c}}$, Xiaoqian $\mathrm{Li}^{1,2, \mathrm{~d}}$ \\ ${ }^{1}$ College of Mechanical and Electrical Engineering, Central South University, Changsha 410083, \\ China \\ ${ }^{2}$ State Key Laboratory of High Performance Complex Manufacturing, Changsha 410083, China \\ ${ }^{3}$ Light Alloy Research Institute, Central South University, Changsha 410083, China \\ achenpinghu1986@163.com, bll187430@126.com, cjiangripeng@163.com, ${ }^{\mathrm{d}}$ meel@csu.edu.cn
}

Keywords: Nozzle parameters, Continuous casting, Temperature field, Flow field, Stress field.

\begin{abstract}
Based on commercial software Pro-CAST, The method of moving boundary was adopted to simulate coupled multi-physical field (temperature field, flow field and stress field) of thick-slab continuous casting in mould. Effect of immerged depth and angle of nozzle were studied to improve characteristics of multi-physical fields. The results show that the immerged depth of $120 \mathrm{~mm}$ to 140 $\mathrm{mm}$ and dip Angle of $15^{\circ}$ is a better parameters for the immerged nozzle. Simulation results are basically identical with the actual result, the obtained parameters of immerged nozzle can provide a certain theoretical basis for the actual casting process.
\end{abstract}

\section{Introduction}

Continuous casting is a process of heat transfer and solidification in essence, the thermal energy is delivered through close contact with steel liquid and solid-liquid-gas medium, such as $\mathrm{Cu}$ mould, cooling water and air. Formation of continuous casting slab have a significant effect on the quality of terminal products[1-4]. In recent years, continuous casting has been a common and efficient casting process in making steel, due to a lot of advantages such as homogeneous microstructure, good mechanical properties and low loss rate[5]. But product's quality simply no longer serves customer demands in the quick science-develops $21^{\text {st }}$ century, material types of continuous casting steel updating constantly, slab thickness is increasing. Therefore, it has become a inevitable technical difficulties to improve the slab quality[6]. The crystallizer is considered the heart of continuous casting machine, which is the key parts ensure quality of continuous casting slabs [7]. Temperature field and flow field in the mould, stress field at the outer of mould and the quality of initial shell are affected by superheat and casting speed (related to nozzle parameters and inserting depth, etc) [8]. Therefore, it has important engineering value to study the interactions with temperature field, flow field, stress field in the mould and the shell thickness at the outer of mould.

Experimental method is the most immediate and efficient way to optimize casting process and structure parameters. The biggest weaknesses are high economic loss and long experimental period. However, numerical simulation is going to be only choice. It have a lot of advantages compared to experimental method. The results is that experimental period is sharply reduced, the human and material resources is substantially reduced. Thus unwanted economic losses is greatly reduced. Finite element method is adopted to study the effect of inserting depth on flow characteristic of liquid steel in the mould[9]. B. Prasad et al[10] design and optimize nozzle parameters by numerical simulation, the results show the quality of casting slab is a big improvement. due to only temperature and flow field are researched by Ruan [9] and B. Prasad [10]. But for the moment, direct coupling temperature-flow-stress field has been reported rarely.

On the base of the previous simulation results, software Pro-Cast and moving boundary method are used to simulate temperature, flow and stress distribution in the mould. Inserting depth and side-hole angle has been considered as the two process parameters which are varied to see their effect on the 
temperature, flow field in the mould and shell thickness, stress distribution at the outer of mould. The optimized parameters of nozzle is regarded as theoretical basis for production and practice in future.

\section{Geometric and Mathematical model}

\subsection{Governing Equations and heat transfer}

The continuity equation can be expressed as (1), while, transient Navier-Stokes equation for momentum conservation can be expressed as (2), and Energy conservation equation for solidification can be defined as (3).

$$
\begin{aligned}
& \frac{\partial \rho}{\partial t}+\nabla \cdot(\rho u)=0 \\
& \nabla \cdot(\rho u u)=-\nabla p+\nabla \cdot\left[\left(\mu+\mu_{t}\right)\left(\nabla u+\nabla u^{T}\right)\right]+\rho G+S \\
& \rho \frac{\partial H}{\partial t}+\rho \nabla \cdot(u H)=\nabla \cdot\left(k_{e f f} \nabla T\right)+Q_{L} \\
& H=h+\Delta H=h_{r e f}+\int_{T_{r e f}}^{T} C_{p} d T+L \cdot f_{L} \\
& \rho \frac{\partial k}{\partial t}+\rho(\nabla k u)=\nabla\left(\alpha_{k}\left(\mu+\mu_{t}\right) \nabla k\right)+G_{k}+\rho \varepsilon+S_{k} \\
& \rho \frac{\partial \varepsilon}{\partial t}+\rho(\nabla \varepsilon u)=\nabla\left(\alpha_{\varepsilon}\left(\mu+\mu_{t}\right) \nabla \varepsilon\right)+C_{1 \varepsilon} \frac{\varepsilon}{k} G_{k}-C_{2 \varepsilon}^{*} \rho \frac{\varepsilon^{2}}{k}+S_{k} \\
& \vec{S}=-\frac{\left(1-f_{l}\right)^{2}}{f_{l}^{2}+\beta} A_{\text {mush }}\left(u-u_{\text {cast }}\right)
\end{aligned}
$$

Where, $\rho=$ density, $u=$ velocity, $G=$ gravity vector, $\mu$ and $\mu_{t}$ are the dynamic and turbulent viscosity, respectively, $Q_{L}=$ source term, $H$ is the enthalpy of the materials and can be computed as the sum of sensible heat $h$ and latent heat content $\Delta H$, can be expressed as (4), the two partial equations for turbulent energy $\kappa$ and dissipation rate $\varepsilon$ model is used for this, can be expressed as (5), $k_{\text {eff }}=$ effective conductivity, $C_{p}=$ specific heat, $L=$ latent heat of material, the momentum sink can be expressed as (6), Amush is mushy zone constant.

\subsection{Boundary conditions and assumptions}

The following assumptions were made during formulation of the solidification model to simplify the governing equations:

$>$ Liquid steel as Newtonian incompressible fluid.

$>$ Mold oscillation and Mold taper, have been ignored.

$>$ Only two dimensional heat transfers is considered, radiative heat transfer has been ignored.

$>\quad$ No slip boundary condition prevails at the walls.

Based on the above assumptions, the materials properties and standard boundary conditions used for analysis in present work. The material type is Q345B steel, the mould size is $230 \mathrm{~mm} \times 1550 \mathrm{~mm}$, height of the mould is $900 \mathrm{~mm}$ and height of liquid steel is $800 \mathrm{~mm}$ in the mould. Liquid steel superheat is $20 \mathrm{~K}$, casting speed is $1.05 \mathrm{~m} / \mathrm{min}$, nozzle angle are $10,15,20$ and 25 degree, respectively. The inserting depth are 100,120,140 and $160 \mathrm{~mm}$, respectively. In the present work, the casting slab length is $1500 \mathrm{~mm}$, schematic diagram as Figure 1. the main boundary conditions are as follows.

$>$ The turbulence intensity and characteristic length can be expressed as (7).

$$
I=0.16 *\left(\frac{v d \rho}{\eta}\right)^{(-1 / 8)}=0.07 L
$$

Where, I is the turbulence intensity, $v$ is the inlet velocity of nozzle. $d$ is hydraulic diameter of nozzle. $\rho$ is medium density. $\eta$ is coefficient of kinetic viscosity. $L$ is characteristic length. 

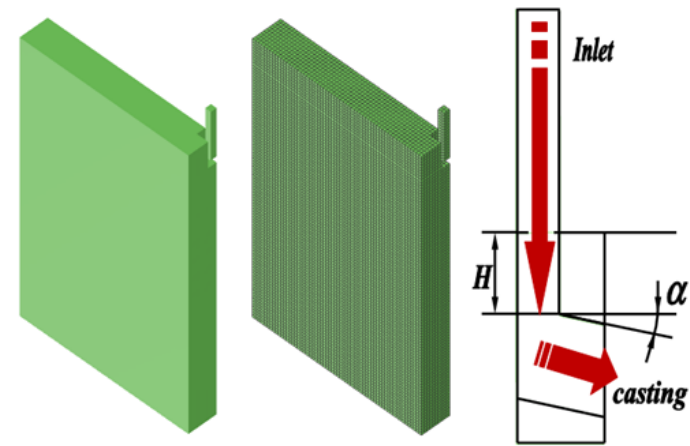

Figure. 1 geometric, mesh model and two dimension schematic diagram of nozzle

In the mould, Heat transfer model between the casting slab and the mould can be expressed as

(8):

$$
q=A-B \sqrt{t}=A-B \sqrt{z / v}
$$

Where, $q$ is heat flux along the height direction of the mould, $\mathrm{MW} / \mathrm{m}^{2} . t$ is pace time for liquid steel in the mould, s. $z$ is the site high for liquid steel in the mould, $\mathrm{m} . v$ is casting speed, $\mathrm{m} / \mathrm{s} ; A$ and $B$ are empirical constant. (9):

$$
h=0.58 W^{0.451}\left(1-0.0075 T_{w}\right)
$$

Where, $h$ is the coefficient of heat transfer, $\mathrm{kW} /\left(\mathrm{m}^{2} \cdot{ }^{\circ} \mathrm{C}\right) ; W$ is water flow density, $\mathrm{L} /\left(\mathrm{m}^{2} \cdot \mathrm{s}\right) ; T_{w}$ is temperature of cooling water, ${ }^{\circ} \mathrm{C}$.

\section{Results and discussion}

\subsection{Effect of Nozzle angle on temperature, flow and stress distribution}

In the first part of investigation, effect of nozzle angle has been studied by the temperature distribution, flow distribution and stress distribution. Figure 2 shows the temperature distribution at the broad face of symmetry plane of mould and secondary cooling zone (SCZ). As can be seen from Figure.2, impact region and high temperature zone of liquid steel have been moved down with nozzle angle increasing. upper recirculation zone is almost high temperature liquid when the nozzle angle is $10^{\circ}$. the superheat is not only larger on the surface of liquid steel, but also liquid levels have a great fluctuation that the oxide inclusion is involved in liquid steel. Thus the steel quality bring down. With the nozzle angle increasing, impact region in narrow face move down and impact depth of the stream become large, but fluctuation and temperature of free surface have a reducing trend. At the same time, involved possibility of inclusion is reduced. Combining the thickness of broad face with narrow face. When the nozzle angle is $10^{\circ}$, poor uniformity is presented in the broad, the thickness difference reaches $6 \mathrm{~mm}$ between the maximum and the minimum. Nevertheless, the difference is fallen between the broad face and the narrow face. At the same time, Fig. 3 shows the distribution of the flow field in the symmetry plane of broad face under the conditions of different nozzle Angle. The results showed that the distribution of flow agree with temperature field in the mould. Effective stress of narrow face and wide face with different nozzle angle in the mould in accordance with fig.4. Effective stress of the shell is increased with the nozzle angle increase. But change of effective stress is not visible when distance is $50 \mathrm{~mm}$ from narrow face and distance is $25 \mathrm{~mm}$ from wide face. In a word, it is suitable that the nozzle angle is about $15^{\circ}$. 


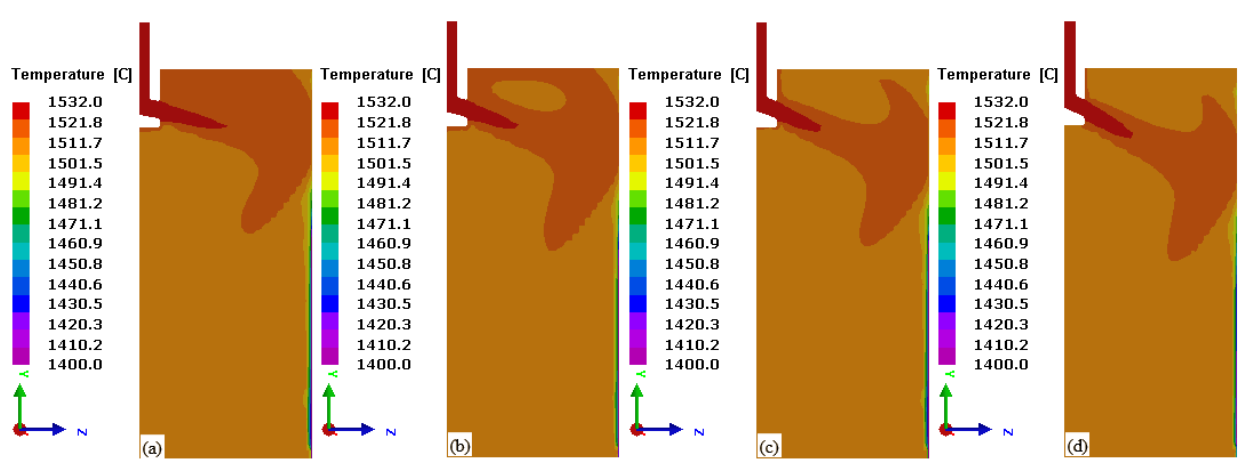

Fig.2 Temperature distribution of different angle in the symmetry of wide face. (a) $10^{\circ}$, (b) $15^{\circ}$, (c)

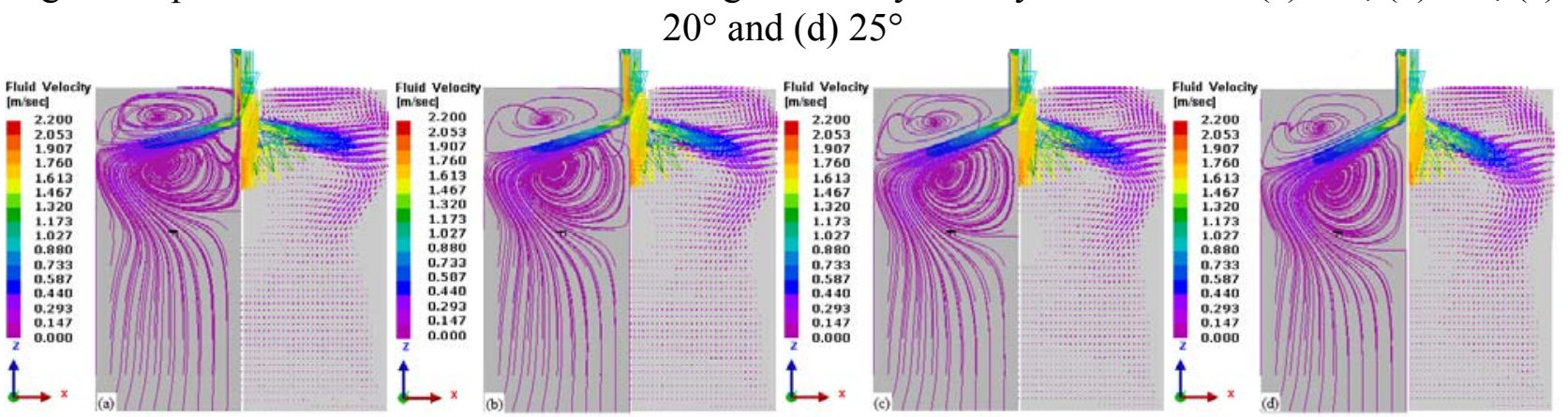

Fig.3 Velocity distribution of different angle in the symmetry of wide face. (a) $10^{\circ}$, (b) $15^{\circ}$, (c) $20^{\circ}$ and (d) $25^{\circ}$

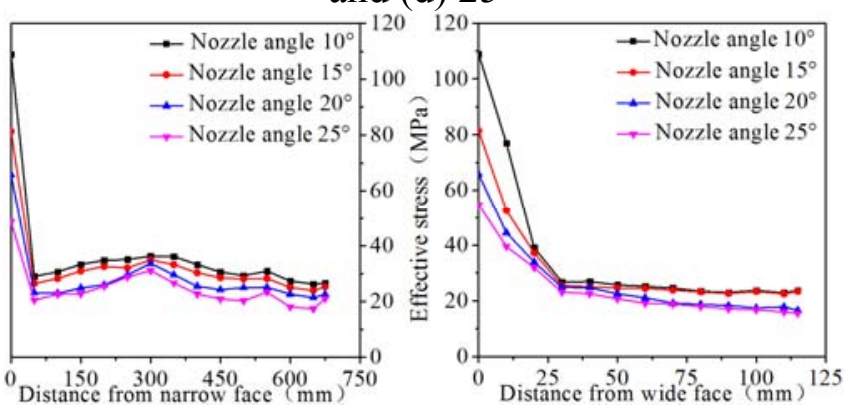

Fig.4 Stress distribution of wide and narrow face with different angle at the exits of mould

\subsection{Effect of inserting depth on temperature, flow and stress distribution}

To study the effect of immerged depth on temperature field, flow field and stress field in the mould. Fig. 5 shows the temperature distribution at the broad face of symmetry plane of mould and secondary cooling zone. Fig. 6 shows the distribution of the flow field in the symmetry plane of broad face under the conditions of different immerged depth. And effective stress of narrow face and wide face with different nozzle angle in the mould in accordance with fig.7. Immerged depth of nozzle is too shallow to cause great disturbance of free liquid surface. And then lead to involvement of mould powder in liquid steel and can cause longitudinal surface cracking. At the same time, Immerged depth of nozzle is too deep to cause great disturbance of free liquid surface ${ }^{[15,16]}$. Combining with the effective stress of narrow face and wide face of the shell in the mould, as shown in fig.7. the effective stress of the shell at the outer of the mould is decreased with the increasing in the immerged depth. To sum up, the optimized immerged depth not only reduce the formation of defects such as mold powder and porosity because of big velocity of free liquid surface, but also avoid the occurrence of breakout accident of casting slab. 

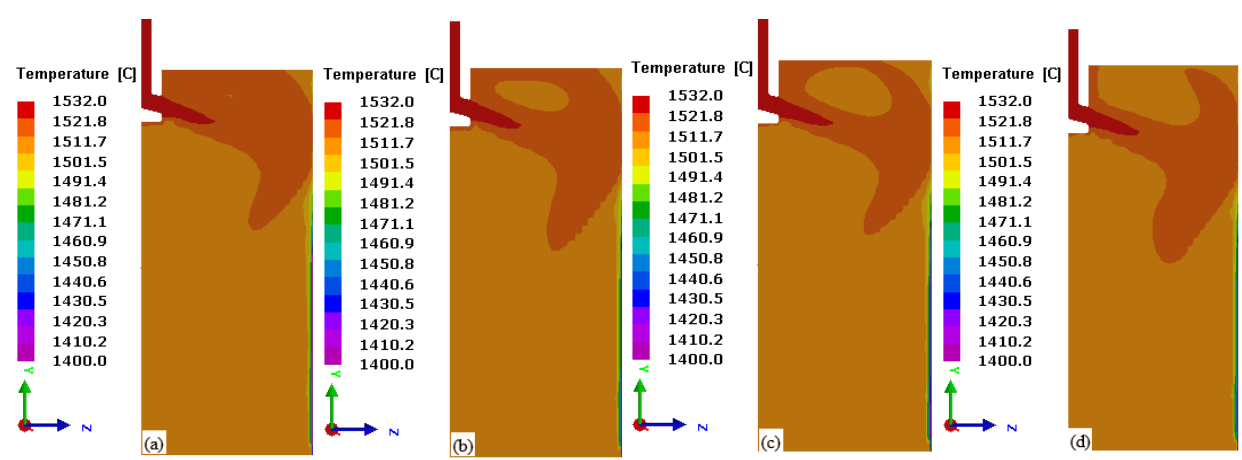

Fig.5 Temperature distribution of different immerged depth in the symmetry of wide face. (a) $100 \mathrm{~mm}$,

(b) $120 \mathrm{~mm}$, (c) $140 \mathrm{~mm}$ and (d) $160 \mathrm{~mm}$
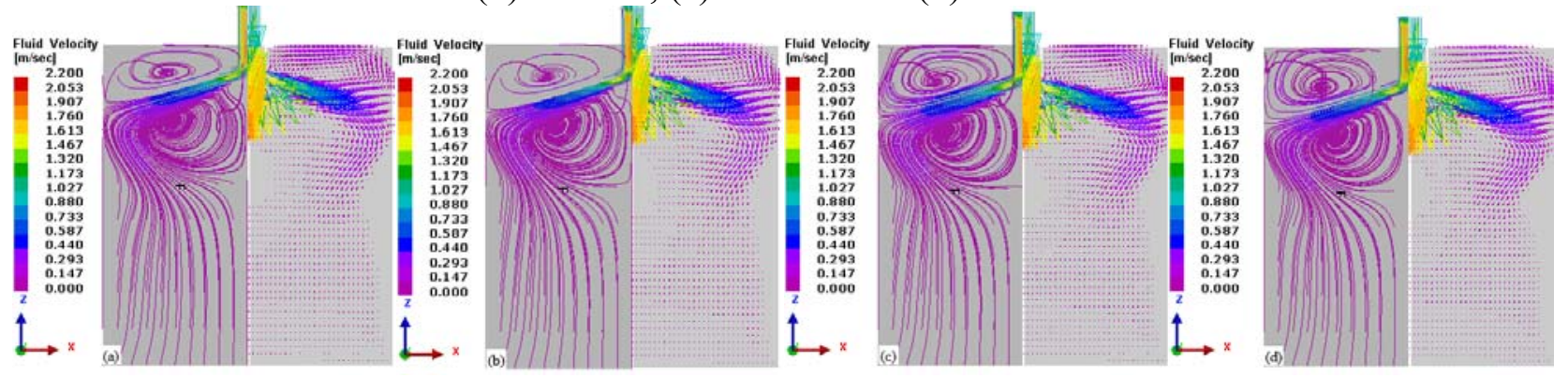

Fig.6 Velocity distribution of different immerged depth in the symmetry of wide face. (a) $100 \mathrm{~mm}$, (b) $120 \mathrm{~mm}$, (c) $140 \mathrm{~mm}$ and (d) $160 \mathrm{~mm}$

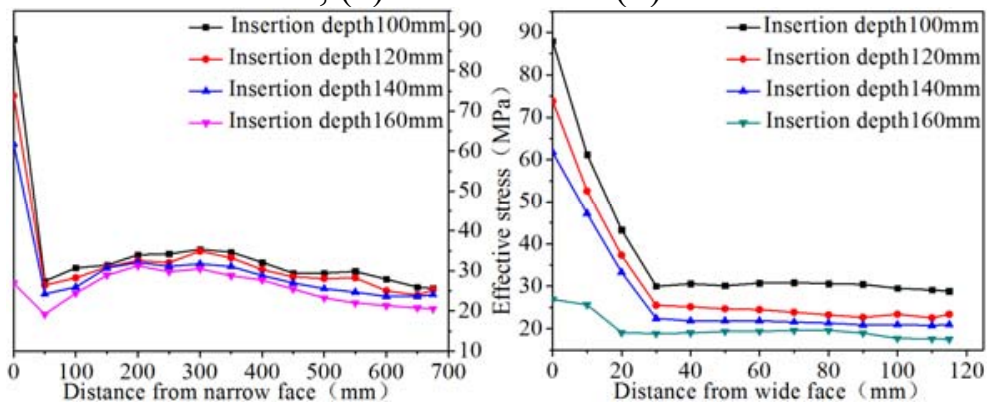

Fig.7 Stress distribution of wide and narrow face with different immerged depth at the exits of mould 3.3 Experimental verification

According to the actual results, the fluctuation range is different with different immersion depth of the nozzle. The fluctuation of liquid level is $1 \mathrm{~mm}$ when the nozzle angle is $90-110 \mathrm{~mm}$. The fluctuation of liquid level are $0.8,0.6$ and $0.4 \mathrm{~mm}$ with immersion depth are ranging from $110-130 \mathrm{~mm}$, $130-150 \mathrm{~mm}$ and $150-170 \mathrm{~mm}$, respectively. Fig. 8 shows the shell thickness are $100 \mathrm{~mm}, 112 \mathrm{~mm}$ and $115 \mathrm{~mm}$, respectively at the position of continuous casting slab. The deviation of experiment results and theoretical results are $-1.85 \%,+2.34 \%$ and $0 \%$. The calculation results are consistent with the simulation results, and the accuracy of the calculation is verified.

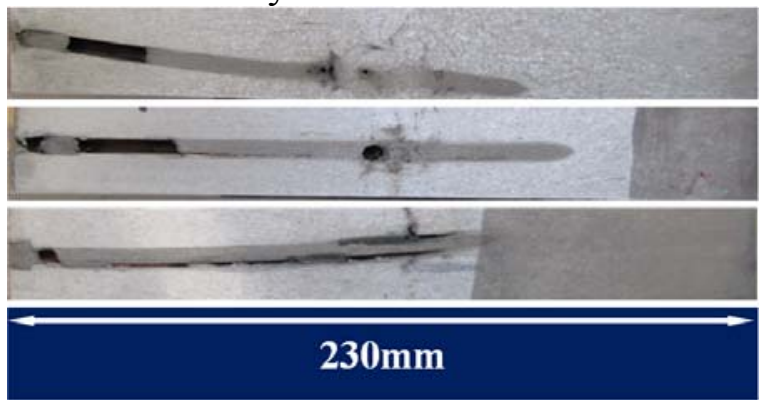

Fig.8 shell thickness and pin shooting experimental results of $230 \mathrm{~mm}$ continuous casting slab 


\section{Conclusion}

In this paper, the structural parameters of the submerged nozzle (nozzle side hole Angle, nozzle inserted depth) is mainly solved in the mould of the continuous casting using the coupled model of flow field, temperature field and stress field. A suitable immerged depth and angle of submerged nozzle is conducive to uniform growth of the shell in the mould. The distribution of temperature, flow and stress field are improved by optimizing parameters of the nozzle. There are suitable parameters that the immersion depth is $120-140 \mathrm{~mm}$ and angle is about $15^{\circ}$ using numerical simulation. The numerical simulation agreed with the actual results.

\section{Acknowledgments}

This project was financially supported by the National Natural Science Foundation of China (Grant No: 51475480) and the State Key Laboratory of High Performance Complex Manufacturing for funding support through No. ZZYJKT2017-01. And this study was supported by the funding of exploratory \& innovative research in Central South University (Grant No: 2015zzts041).

\section{References}

[1] Ambrish Maurya and Pradeep Kumar Jha. EFFECT OF CASTING SPEED ON CONTINUOUS CASTING OF STEEL SLAB [J]. International Journal of Mechanical Engineering and Robotics Research, 2014, 1(1): 13-21.

[2] T. TELEJKO, Z. MALINOWSKI, M. RYWOTYCKI. ANALYSIS OF HEAT TRANSFER AND FLUID FLOW IN CONTINUOUS STEEL CASTING [J]. ARCHIVES OF METALLURGY AND MATERIALS, 2009, 54(3): 837-843.

[3] DONG Fang, WANG Zhang-ling, LI Jian-chao, et al. Numerical simulation of temperature field for heavy slab during continuous casting [J]. Journal of Inner Mongolia University of Science and Technology, 2012, 31(1): 14-18.

[4] CHEN Hui, ZHANG Li, ZHAO Su, et al. Research Progress in Central Segregation Control in Continuous Casting [J]. Hot Working Technology, 2012, 41(9): 45-48.

[5] R. Vertnik, B. arler. Solution of a continuous casting of steel benchmark test by a meshless method [J]. Engineering Analysis with Boundary Elements, 2014, 45: 45-61.

[6] Feng Shichao, Wang Yanhong, Ding Ruifeng. PROGRESS IN INVESTIGATION OF ELECTROMAGNETIC TECHNOLOGY APPLICATION IN CONTINUOUS CASTING BOTH AT HOME AND ABROAD [J]. Shanghai Metals, 2014, 36(3): 47-55.

[7] Mei FengYan, ChaohongRuan, Xiaoming, et al. Research and Development of Solidification and Heat Transfer Models for Mould of Baosteel's Heavy-plate Continuous Caster [J]. BAOSTEEL TECHNOLOGY, 2008, 1: 63-67.

[8] Brian G. Thomas, Seid Koric, Lance C. Hibbeler, et al. Metaphysics Model of Continuous Casting of Steel Beam-Blanks [C]. The 4th International Conference on Modelling and Simulation of Metallurgical Process in Steelmaking, Dusseldorf, Germany, 2011.

[9] Ruan Fei, Zhao Fengguang, Fu Xiaoyang, et al. Influence of Immersion Depth of Mubmersed Nozzle on Molten Steel Flow Characteristic in Mould for H-Beam Blank Continuous Casting [J]. Metallurgical Equipment, 2015, 218: 11-15.

[10] B.Prasad, JK.Sahu, JN.Tiwari, et al. Designing of Sub-entry Nozzle for Casting Defect-free Steel[C]. IOP Conference Series Materials Science and Engineering, 2015, 75(1):1-6.

[11] Sheng Yiping. THE ORETIC STUDY AND PRACTICAL APPLICATION ON NEW TYPE HIGH SPEED CONTINUOUS CASTING MOLD [D]. Qinhuangdao: Yanshan University, 2007.

[12] Sheng Yiping, Kong Xiangdong, Yang Yongli. Study on Thermal Boundary Conditions in the Mold for Continuous Casting [J]. CHINA MECHANICAL ENGINEERING, 2007, 18(13): 1615-1618.

[13] Camisani-Calzolari F R, Craig I K, Pistorius P C. Control strategies for the secondary cooling 
zone in continuous casting [M]. 1999.

[14] Miłkowskapiszczek K, Rywotycki M, Falkus J, et al. A Comparison of Models Describing Heat Transfer in the Primary Cooling Zone of a Continuous Casting Machine [J]. Archives of Metallurgy \& Materials, 2015, 60(1): 239-244.

[15] Nordquist A, Kumbhat N, Jonsson L, et al. The Effect of Nozzle Diameter, Lance Height and Flow Rate on Penetration Depth in a Top - blown Water Model [J]. Steel Research International, 2010, 77(2):82-90.

[16] Zhang W, Gao J, Rohatgi P K, et al. Effect of the depth of the submerged entry nozzle in the mold on heat, flow and solution transport in double-stream-pouring continuous casting [J]. Journal of Materials Processing Technology, 2009, 209(15-16): 5536-5544. 